\title{
Socioeconomic Differences in the Prevalence of Care Need among Older Persons in Ghana
}

\author{
Bashiru II Saeed ${ }^{\star *}$, Alfred Yawson ${ }^{2}$, Emmanuel Nakua ${ }^{3}$, Peter Agyei-Baffour ${ }^{3}$, Nicholas NN Nsowah-Nuamah ${ }^{4}$ and Baddoo Daniel ${ }^{5}$ \\ ${ }^{1}$ Department of Mathematics and Statistics, Kumasi Polytechnic, Ghana \\ ${ }^{2}$ Department of Community Health, University of Ghana School of Public Health, College of Health Sciences, Korle-Bu, Accra, Ghana \\ ${ }^{3}$ Department of Community Health, College of Health Sciences, Kwame Nkrumah University of Science and Technology, Kumasi \\ ${ }^{4}$ Rector, Kumasi Polytechnic, Ghana \\ ${ }^{5}$ Orthopaedic Unit, Department of Surgery, Korle-Bu Teaching Hospital, Accra, Ghana
}

\begin{abstract}
Background: Healthcare is a great predictor of increased longevity and well-being but there is paucity of data on the prevalence of and socioeconomic differences in care need among the aged in low- to middle- income countries including Ghana.
\end{abstract}

Objective: The goal of this study is to provide timely research based knowledge of the socioeconomic differences in the prevalence of care need among older persons in Ghana which will be crucial in guiding the implementation of the 2010 National Aging Policy (Ghana National Ageing Policy, 2010).

Method: The World Health Organization (WHO) Study on global AGEing and Adult Health (SAGE) conducted in 2007-2008 among older adult Ghanaians included sociodemographic and socioeconomic factors and measures of health care needed by these older persons. This study considered $2313(51.9 \%)$ men and $2141(48.1 \%)$ women. Analyses of the association of care need with predisposing and enabling factors was by binary logistic regression analysis, using odds ratios (OR) and the respective $95 \%$ confidence intervals.

Results: This study showed sex differentials in care need among older persons. Older women were more affected by socioeconomic difference in care need. Older persons with lower education had a high prevalence of care need (for both men and women). Self-employed older persons were the highest in terms of care need and those with moderate, little or no money for daily living showed high rates of care need compared to those who had enough money.

Conclusion: Implementation of the 2010 national aging policy should address these gender disparities and socioeconomic differences in care need among older persons in Ghana

Keywords: Care need; Socioeconomic status; Sex differentials; Older persons; Ghana

\section{Background}

Care is provided in the community to help people who may need it and support to maintain their independence. The need for longterm care arises from various causes, including diseases, disabling chronic conditions, injury, severe mental illness, and developmental disabilities. Generally, community care services are available to people adversely affected by illness, disability, old age, alcohol or drug related problems. In estimating the number of people with long-term care needs, researchers usually define a person as needing long term care if he or she requires another person's help with one or more activities of daily living (ADLs) or instrumental activities of daily living (IADLs) [1]. ADLs are fundamental tasks, defined here to include bathing, eating, dressing, using the toilet, getting in and out of a bed or chair, and getting around inside the home. IADLs are additional activities necessary for independence, such as meal preparation, managing money, managing medications, using the telephone, doing light housework, and shopping for groceries and other necessities. The proportion of older people is increasing in almost all countries of the world and Ghana is no exception [2]. This is due to population ageing, a demographic trend in which there is a decline in both birth rate and death rate in a population [3]. With an increase in life expectancy, adults will continue to live to the "ripe" old age.

Post retirement period is associated with physical and social challenges. Within an economic and political context, retirement ages and the ages at which individuals become eligible for aged-related benefits are determined based on different criteria. Official retirement ages have steadily increased and there are significant variations between countries for official retirement ages, and between sexes. In China, for example, the retirement age is generally around 60 years for men and 50-55 years for women respectively; however, in some labor-intensive jobs, it may be 5 years earlier [4]. Special health care needs include any physical, developmental, mental, sensory, behavioral, cognitive, or emotional impairment or limiting condition that requires medical management, health care intervention, and/or use of specialized services. Population ageing is a global phenomenon, affecting both developed and developing nations, with attendant implications for health policy and future systems of care. Older individuals are living for much longer, with a significant burden of chronic disease, disability and impairments in cognition, sight, hearing and mobility. Despite this, the bulk of evidence at present seems to indicate that the onset of disability is being postponed, supporting the notion of the "compression of morbidity" [5]. The capacity to meet the healthcare

*Corresponding author: Bashiru II Saeed, Department of Mathematics and Statistics, Kumasi Polytechnic, Ghana, Tel: +233(20)8204092; E-mail: sirbash156@gmail.com

Received September 24, 2015; Accepted November 02, 2015; Published November 09, 2015

Citation: Saeed B, Yawson A, Nakua E, Agyei-Baffour P, Nsowah-Nuamah NNN, et al. (2015) Socioeconomic Differences in the Prevalence of Care Need among Older Persons in Ghana. Health Econ Outcome Res Open Access 1: 102. doi: $10.4172 / 2471-268 x / 1000102$

Copyright: $\odot 2015$ Saeed B, et al. This is an open-access article distributed unde the terms of the Creative Commons Attribution License, which permits unrestricted use, distribution, and reproduction in any medium, provided the original author and source are credited. 
needs of an increasingly older adult population represents a significant challenge for public health globally. Many of the oldest-old lose their ability to live independently because of limited mobility, frailty, or other declines in physical or cognitive functioning [5]. Many require some form of long term care, including home nursing, community care and assisted living. The costs associated with providing this support may need to be borne by families and society [6].

In less developed countries where established and affordable long-term care infrastructure is lacking or inadequate, this cost may have catastrophic effect on the family, that is, other family members withdrawing from employment or school to care for older relatives [7]. In many developing countries, younger members of the family move to the cities and urban areas to seek jobs and the older relatives back home have less access to informal family care and support. The future need for long-term care services (both formal and informal) will largely be determined by changes in the absolute number of people in the oldest age groups coupled with trends in disability rates [8]. Given the increases in life expectancy and the sheer numeric growth of older populations, demographic momentum will likely raise the demand for care. This growth could, however, be alleviated by declines in disability among older people. Further, the narrowing gap between female and male life expectancy reduces widowhood and could mean a higher potential supply of informal care by older spouses [8]. The need to have longevity with quality is to keep older people healthy longer, delaying or avoiding disability and dependence.

According to the National Nursing Home Survey in 1999 in the United States, nearly 10 million people need long-term care [9-14], that is, need help with ADLs or IADLs. Most were aged 65 years and the risk of needing long-term rise steeply with age. Half of the older persons 85 years and older, needed some long-term care [9]. Sex differences exist in the care needs of older persons, majority being women, among nursing home residents of all ages, 72 percent are women [10]. Not surprisingly, the need for long-term care is often accompanied by other health-related needs. About two-thirds of adults living at home with long-term care needs are in fair or poor health. Furthermore, among community-dwelling older adults, those with long-term care needs had more health needs compared with community-dwelling older adults without long-term care needs [2].

In Ghana, there is paucity of research based information on the exact care needs of the aged population. The goal of this analysis is to provide timely research based knowledge of the socioeconomic differences in the prevalence of care need among older persons in Ghana which will be crucial in guiding the implementation of the 2010 National Aging Policy [11].

\section{Material and Method}

\section{Sampling procedures}

The data employed in this study were drawn from the World Health Organization Global Ageing and Adult Health (SAGE). This aims to evaluate the association of the care need and socio-demographic and socio-economic differences among older male and female Ghanaians [15-19]. It also aims at addressing the gap in reliable data and scientific knowledge on ageing and health in low - and middle-income countries. SAGE is a longitudinal study with nationally representative samples of persons aged 50+ years in Ghana with a smaller sample of adults aged 18-49 years. Wave 1 was conducted during 2007-2008 and included a total of 4770 respondents aged $50+$ and 803 aged $18-49$. In this study, 2313 (51.9\%) men and 2141 (48.1\%) women were involved. Face-to- face interview was conducted in Ghana (2007-2008). Multistage cluster sampling strategies were used to select households. Household-level analysis weights and person-level analysis weights were calculated for each country, which included sample selection and a post-stratification factor [20]. Post stratification correction techniques used the most recent population estimates provided by the Ghana Statistical Service. The pooled Wave 1 national total for individual respondents included 4770 respondents aged 50+ and 803 aged 18-49. A standardized survey instrument, set of methods, interviewer training and translation protocols are used in all SAGE countries [5].

\section{Measures of care needed}

Information of care needed was elicited in one question. The respondents were asked if they needed care due to their health conditions or because they are getting old and weak.

\section{Socio-demographic and socio-economic measures}

Predisposing measures were age (age 18-49 (young adults), 50-59 (adults) and 60yrs and above (older adults)), gender and marital status (currently married, never married, cohabitating, separated/divorced and widowed).

Enabling measures were assessed in terms of education, job employment, well-being and income. Education was recorded as college/university completed, high school completed, secondary school completed, primary school completed, less than primary school completed and no formal education.

Job employment was categorized into four groups: public, private, self-employed and informal employment. Public sector includes employees of state, or municipal governments and their agencies, and parastatal enterprises. Private sector includes any employees not working for the government and not self-employed [21-23]. Selfemployed includes those who earn their livelihood directly from their own trade or business rather than as an employee of another. Informal economy refers to the general market income category and income generations are unregulated by the institutions of society. Jobs in the informal economy are characteristically without benefits such as health insurance, sick leave, paid vacations or pensions.

Well-being status was recorded as completely, mostly, moderately, a little and not at all. Wealth or income Quintiles, Q1 (lowest) through Q5 (highest) were derived from the household ownership of durable goods, dwelling characteristics (type of floors, wells and cooking stove), and access to services (improved water, sanitation and cooking fuel) for a total of 21 assets. A two-step random effects probit model was used to generate the Quintiles [3].

\section{Statistical methods}

Age-adjusted prevalence rates on all respondents were first computed for descriptive purposes. Analyses of care need with sociodemographic and socio-economic factors were carried out distinctively for men, women and both sexes by means of binary logistic regression analysis. Odds ratios (OR) and their respective 95\% confidence intervals were also computed. Firstly, all variables in the analysis were unadjusted for each other. Secondly, each variable was adjusted for age (age-adjusted model). Those whose ages are less than 50 years, married, have no formal education, in the public sector and have the lowest income were used as the comparison group for all individual data outcomes [24]. To examine how the observed associations of socio-demographic and socio-economic indicators with care need may change when several of these indicators are considered simultaneously, 
age-unadjusted and age-adjusted odds ratios from logistic regression analyses were compared. Stata SE (version 12.1) was used for analysis.

\section{Fitted Logistic Regression Model}

Given a logistic regression model,

$$
\operatorname{logit}\left(\pi\left(x_{i}\right)\right)=\log \left(\frac{\pi\left(x_{i}\right)}{1-\pi\left(x_{i}\right)}\right)=\beta_{0}+\beta_{1} x_{1}+\beta_{2} x_{2}+\ldots+\beta_{q} x_{q}
$$

We observed the outcome of the independent binomial trials with probability $\pi\left(x_{i}\right)$. Let $y_{i}$ be the observed responses. Then, the total likelihood is

$$
L=\prod_{i=1}^{n}\left[\exp \left(y_{i} \log \left(\frac{\pi\left(x_{i}\right)}{1-\pi\left(x_{i}\right)}\right)\right)+\log \left(1-\pi\left(x_{i}\right)\right)\right]
$$

and so the log-likelihood is

$$
\ell=\sum_{i} y_{i} \log \left(\frac{\pi\left(x_{i}\right)}{1-\pi\left(x_{i}\right)}\right)+\sum_{i} \log \left(1-\pi\left(x_{i}\right)\right)
$$

Since,

$$
\log \left(\frac{\pi\left(x_{i}\right)}{1-\pi\left(x_{i}\right)}\right)=\beta^{T} X
$$

For some unknown vector of $\beta$ where $\pi\left(x_{i}\right)=\frac{1}{1+e^{-\beta X}}$

Using the maximum likelihood to fit the model yields a set of equations to solve from considering

$$
\frac{\partial \ell}{\partial \beta}=0, \frac{\partial \ell}{\partial \beta}=\sum_{i} y_{i} x_{i}-\sum_{i}\left(\frac{x_{i}}{1+e^{-\beta X}}\right)=\sum_{i} y_{i} x_{i}-\sum_{i} \pi\left(x_{i}\right) x_{i}
$$

By using the assumed linear relation between the log odds and the predictors, this means that the MLE satisfies $\sum_{i} y_{i} x_{i}=\sum \pi\left(x_{i}\right) x_{i}$

Since MLEs are invariant under transformation hence $\hat{\pi}\left(x_{i}\right)=\frac{1}{1+e^{-\beta^{T} X}}$ if $x_{i}$ has a component of $j$ that is always 1 , for every $i$ then $\sum y_{i} x_{i}=\sum y_{i}=\hat{\pi}\left(x_{i}\right)$, hence the empirical proportion of the positive response matches the average of the fitted probabilities.

The logistic model for $\pi\left(x_{i}\right)$ is the probability of the care need for a given value of the predictors,

$$
\operatorname{logit}\left(\pi\left(x_{i}\right)\right)=\log \left(\frac{\pi\left(x_{i}\right)}{1-\pi\left(x_{i}\right)}\right)=\beta_{0}+\beta_{1} x_{1}+\beta_{2} x_{2}+\ldots+\beta_{q} x_{q}
$$

where $x_{i}$ are the predictors

$$
x_{i}=\left\{\begin{array}{c}
1, \text { if exposed to factor } \\
0, \text { if not exposed to factor }
\end{array}\right.
$$

For $x=0$,

$$
\operatorname{logit}\left(\pi\left(x_{i}\right)\right)=\log \left(\frac{\pi\left(x_{i}\right)}{1-\pi\left(x_{i}\right)}\right)=\alpha+\beta(0)=\alpha
$$

For $x=1$,

$$
\operatorname{logit}\left(\pi\left(x_{i}\right)\right)=\log \left(\frac{\pi\left(x_{i}\right)}{1-\pi\left(x_{i}\right)}\right)=\alpha+\beta(1)=\alpha+\beta
$$

The odds of the disease (care need) when $x=0$ is $\left(\frac{\pi(0)}{1-\pi(0)}\right)$.
The odds of the disease (care need) when $x=1$ is $\left(\frac{\pi(1)}{1-\pi(1)}\right)$.

The Odds Ratio (OR) of the condition (care need) = $\left(\frac{\text { The odds of care need when } x=1}{\text { The odds of care need when } x=0}\right)=\frac{\frac{\pi(1)}{1-\pi(1)}}{\frac{\pi(0)}{1-\pi(0)}}$

Since

$$
\begin{aligned}
& \beta=\log \left(\frac{\pi(1)}{1-\pi(1)}\right)-\log \left(\frac{\pi(0)}{1-\pi(0)}\right) \\
& \beta=\log \frac{\left(\frac{\pi(1)}{1-\pi(1)}\right)}{\left(\frac{\pi(0)}{1-\pi(0)}\right)}
\end{aligned}
$$

This implies that

$$
\mathrm{OR}=\exp ^{\beta}
$$

\section{Results}

\section{Prevalence of care need by socio-demographic variables}

In our preliminary results, $85.4 \%$ (persons $50+$ years) and $14.6 \%$ (persons 18-49 years) reported they needed care. The prevalence of care need was $15.3 \%$ among young male adults (18-49 years), 35.5\% among male adults (50-59 years) and $49.2 \%$ among older male adults $(\geq 60$ years) respectively (Table 1) A similar pattern of care need increasing with age was observed among females, young adult females (14.4\%), adult females (30.5\%) and older adult females (55.1\%) respectively. Men who are currently married needed care more often than other men whereas women who are widowed needed care more often than other women (Table 2).

\section{Prevalence of care need by socio-economic variables}

An educational gradient was found for care need: but in high school completed, the lower the education, the higher the prevalence of care need for both men and women. However, the self-employed had the highest percentage in terms of care need for both men and women in the employment category (Table 2).Care need varied by income status. Ghanaians who have moderate, little and no money showed high rates of care need as compared to those who have enough money [25-27]. Sex difference in socioeconomic status and care need existed; was wider among women compared to men.

Associations between different care outcomes and sociodemographic and socio-economic variables among men

Among men, care need was statistically significantly associated with both education and job employment in the age-unadjusted

\begin{tabular}{|l|c|c|c|}
\hline Age Category & Male & Female & Both Sexes \\
\hline & Care need \% & Care need \% & Care need \% \\
\hline $18-49$ & 15.3 & 14.4 & 14.9 \\
\hline $50-59$ & 35.5 & 30.5 & 33.1 \\
\hline $60+$ & 49.2 & 55.1 & 52 \\
\hline
\end{tabular}

Table 1: Prevalence (\%) and 95\% confidence intervals (Cl) for care need by age. 
Citation: Saeed B, Yawson A, Nakua E, Agyei-Baffour P, Nsowah-Nuamah NNN, et al. (2015) Socioeconomic Differences in the Prevalence of Care Need among Older Persons in Ghana. Health Econ Outcome Res Open Access 1: 102. doi: 10.4172/2471-268x/1000102

Page 4 of 6

\begin{tabular}{|l|c|c|c|}
\hline & Male & Female & Both Sexes \\
\hline & Care need & Care need & Care need \\
\hline Marital Status & $\%$ & $\%$ & $\%$ \\
\hline currently Married & 83.1 & 31.3 & 58.2 \\
\hline never married & 2.4 & 2.5 & 2.4 \\
\hline cohabitating & 1.2 & 1.3 & 1.2 \\
\hline separated / divorced & 7.4 & 20.1 & 13.5 \\
\hline widowed & 6.0 & 44.8 & 24.7 \\
\hline Highest Educational Level & & & \\
\hline no formal education & 37.6 & 59.2 & 48.0 \\
\hline less than primary school & 10.7 & 13.4 & 12.0 \\
\hline primary school completed & 14.6 & 10.1 & 12.5 \\
\hline secondary school(O\&A levels) & 8.6 & 3.4 & 6.1 \\
\hline completed & & & \\
\hline high school (or equivalent) completed & 23.6 & 11.9 & 17.9 \\
\hline college/university completed & 5.0 & 2.0 & 3.6 \\
\hline Job Employment & & & \\
\hline public & 13.6 & 5.0 & 9.5 \\
\hline private & 6.1 & 2.1 & 4.2 \\
\hline self-employed & 73.3 & 86.2 & 79.5 \\
\hline informal employment & 7.0 & 6.7 & 6.9 \\
\hline INCOME & & & \\
\hline Q1 & 17.2 & 19.8 & 18.4 \\
\hline Q2 & 18.8 & 20.0 & 19.4 \\
\hline Q3 & 19.7 & 20.3 & 20.0 \\
\hline Q4 & 21.1 & 21.2 & 21.2 \\
\hline Q5 & 23.2 & 18.6 & 21.0 \\
\hline WELL-BEING & & & \\
\hline Completely & 1.6 & 1.2 & 1.4 \\
\hline Mostly & 26.7 & 5.1 & 5.4 \\
\hline Moderately & 43.6 & 22.1 & 24.5 \\
\hline a Little & 22.5 & 27.5 & 48.8 \\
\hline not at all & & 24.9 \\
\hline Table & & \\
\hline
\end{tabular}

Table 2: Age-adjusted prevalence (\%) for care need by socio-demographic and socio-economic indicators.

models, and tended to be lower in non-public sector and those who do not have just enough money to meet their needs (Table 3). In the age-adjusted model, the indicators remained statistically significantly associated with care need and tended to be lower in the adult and older adult groups, non-public sector and those who do not have just enough money to meet their needs (Table 3). Those having less than primary education, completed primary and senior secondary schools were clearly strongly more likely to receive care than those with no formal education in the age-unadjusted models. After adjusting for age, the situation remained unchanged except secondary school completed [28]. Self-employed and informal employees were however less likely to receive care than public employees. It remained same even after adjusting for age. Nevertheless, both income and marital status showed weak and inconsistent association with care need in both ageunadjusted and age-adjusted models. In both age-unadjusted and ageadjusted models, statistically, care need was weakly associated with well-being, marital status and income.

\section{Associations between different care outcomes and socio-} demographic and socio-economic variables among women

Among women, care need was inconsistently associated with all studied variables except job employment in both age-adjusted and age-

unadjusted models (Table 3). This association remained unchanged after readjusting for all studied variables. However, care need among women was associated with older adults. In contrast to men, care need among women was also associated with higher educational level as college/university graduates were less likely to receive care than those women who have no formal education. Among women, care need showed association with relatively middle income quintile (Q3). In contrast to men, there was the statistically significant association with women [29]. The third quintile (Q3) was more likely to receive care need than first quintile (Q1). After age was adjusted for all studied variables, the situation remained unchanged. Among both sexes, care need was significantly associated with all studied variables except income for both age-unadjusted and age-adjusted models.

\section{Discussion}

Our analysis confirmed that care need is a phenomenon among ageing Ghanaians. The study revealed that $85.4 \%$ (persons $50+$ years) and $14.6 \%$ (persons $18-49$ years) of the survey population reported they needed care. According to literature, older individuals are living for much longer, with a significant burden of chronic disease, disability and impairments in cognition, sight, hearing and mobility (6).

According to (9), nearly 10 million people need long-term care in the United States (9); that is, need help with ADLs or IADLs. Most of these are aged 65 years and the risk of needing long-term rise steeply with age. Half of the older persons 85 years and older, needed some long-term care (9). In this analysis, the prevalence of care need was $15 \%$ among young male adults, 36\% among male adults and $49 \%$ among older male adults respectively Care need also increased with age among females, young adult females (14\%), adult females (31\%) and older adult females (55\%) respectively. Clearly, this goes to buttress the point that older persons require more supportive care and that care for older persons in Ghana should be one of the pillars for implementing the 2010 National Aging Policy.

This analysis revealed that women were mostly affected by socioeconomic difference in care need and that care need was highest for the older women (60 years or more), compared to the adult and younger adult females. This agrees with findings from some previous studies which indicated that more women need long-term care (9) and also among community residents (aged 18 to 64, and those aged 65 and older) who require long term care are women. In addition nursing home residents of all ages, 72 percent are women (10).

Among both men and women, those with lower education had a high prevalence of care need and the self-employed persons had the highest care need. . Also, older persons with moderate, little or no money showed high rates of care need compared to those who had enough money. Kinsella and He in a study in 2009 indicated that in developed countries with limited established and affordable long-term care infrastructure, the cost of care need for older persons was in the form of other family members withdrawing from employment or school to care for their older relatives. [7] In contrast, in developing countries, residents looked for jobs in the cities or other urban areas while their older relatives back home had less access to informal family care.

Among older persons in this national survey, the self-employed and informal employees were less likely to receive care than public employees. Probably, access to pension by public sector employees may improve access to care need. As demonstrated in the analysis, care need for women was consistently associated with job employment. 
Citation: Saeed B, Yawson A, Nakua E, Agyei-Baffour P, Nsowah-Nuamah NNN, et al. (2015) Socioeconomic Differences in the Prevalence of Care Need among Older Persons in Ghana. Health Econ Outcome Res Open Access 1: 102. doi: 10.4172/2471-268x/1000102

Page 5 of 6

\begin{tabular}{|c|c|c|c|c|c|c|}
\hline & \multicolumn{2}{|c|}{ Male } & \multicolumn{2}{|c|}{ Female } & \multicolumn{2}{|c|}{ Both } \\
\hline & Age Adjusted & Age Unadjusted & Age Adjusted & Age Unadjusted & Age Adjusted & Age Unadjusted \\
\hline & OR & OR & OR & $\mathrm{OR} \quad \mathrm{Cl}$ & OR & OR \\
\hline \multicolumn{7}{|l|}{ AGE } \\
\hline $18-49$ & 1 & & 1 & & 1 & \\
\hline $50-59$ & $0.86(0.58,1.27)$ & & $0.79(0.50,1.24)$ & & \multicolumn{2}{|c|}{$0.79(0.59,1.06)$} \\
\hline $60+$ & $0.82(0.56,1.20)$ & & $1.10(0.69,1.78)$ & & \multicolumn{2}{|c|}{$0.86(0.64,1.16)$} \\
\hline \multicolumn{7}{|l|}{ Marital Status } \\
\hline currently Married & 1 & 1 & 1 & 1 & 1 & 1 \\
\hline never married & $0.80(0.36,1.77)$ & $0.85(0.39,1.86)$ & $0.92(0.37,2.32)$ & $0.99(0.40,2.47)$ & $0.90(0.50,1.63)$ & $0.95(0.53,1.71)$ \\
\hline cohabitating & $0.58(0.22,1.49)$ & $0.58(0.23,1.50)$ & $1.05(0.30,3.69)$ & $1.07(0.31,3.72)$ & $0.76(0.36,1.60)$ & $0.78(0.37,1.63)$ \\
\hline separated/divorced & $1.19(0.74,1.91)$ & $1.16(0.73,1.87)$ & $0.72(0.50,1.03)$ & $0.73(0.52,1.04)$ & $0.97(0.76,1.25)$ & $0.96(0.75,1.23)$ \\
\hline widowed & $0.94(0.59,1.50)$ & $0.91(0.57,1.45)$ & $0.97(0.69,1.36)$ & $1.06(0.78,1.44)$ & $1.26(1.01,1.57)$ & $1.26(1.02,1.55)$ \\
\hline \multicolumn{7}{|l|}{ Highest Educational Level } \\
\hline no formal education & 1 & 1 & 1 & 1 & 1 & 1 \\
\hline less than primary school & $2.35(1.47,3.75)$ & $2.40(1.50,3.82)$ & $0.94(0.65,1.38)$ & $0.90(0.62,1.31)$ & $1.36(1.02,1.82)$ & $1.37(1.03,1.82)$ \\
\hline primary school completed & $2.09(1.37,3.20)$ & $2.18(1.44,3.31)$ & $1.26(0.77,2.07)$ & $1.18(0.73,1.91)$ & $1.60(1.16,2.20)$ & $1.63(1.19,2.23)$ \\
\hline secondary school completed & $1.62(0.94,2.77)$ & $1.70(1.00,2.88)$ & $1.57(0.59,4.18)$ & $1.50(0.58,3.92)$ & $1.40(0.88,2.23)$ & $1.44(0.91,2.28)$ \\
\hline high school (or equivalent) completed & $0.96(0.70,1.31)$ & $0.99(0.73,1.33)$ & $1.25(0.77,2.01)$ & $1.11(0.70,1.76)$ & $0.92(0.71,1.18)$ & $0.91(0.71,1.17)$ \\
\hline college / university completed & $1.75(0.76,4.05)$ & $1.80(0.78,4.16)$ & $0.30(0.12,0.74)$ & $0.28(0.11,0.69)$ & $0.84(0.46,1.51)$ & $0.84(0.46,1.51)$ \\
\hline \multicolumn{7}{|l|}{ Job Employment } \\
\hline public & 1 & 1 & 1 & 1 & 1 & 1 \\
\hline private & $0.80(0.38,1.66)$ & $0.81(0.39,1.69)$ & $0.99(0.28,3.49)$ & $0.96(0.27,3.36)$ & $0.83(0.44,1.56)$ & $0.84(0.45,1.58)$ \\
\hline self-employed & $0.44(0.27,0.71)$ & $0.45(0.28,0.72)$ & $0.60(0.28,1.31)$ & $0.60(0.28,1.29)$ & $0.50(0.33,0.75)$ & $0.51(0.34,0.76)$ \\
\hline informal employment & $0.36(0.20,0.67)$ & $0.37(0.20,0.68)$ & $0.47(0.19,1.14)$ & $0.47(0.19,1.13)$ & $0.40(0.25,0.65)$ & $0.41(0.25,0.66)$ \\
\hline \multicolumn{7}{|l|}{ Well-Being } \\
\hline Completely & 1 & 1 & 1 & 1 & 1 & 1 \\
\hline Mostly & $0.6(0.13,2.84)$ & $0.59(0.13,2.81)$ & $0.96(0.19,4.82)$ & $0.93(0.19,4.64)$ & $0.73(0.24,2.23)$ & $0.73(0.24,2.21)$ \\
\hline Moderately & $0.47(0.11,2.01)$ & $0.46(0.11,2)$ & $1.06(0.24,4.75)$ & $1.04(0.23,4.66)$ & $0.64(0.23,1.81)$ & $0.64(0.23,1.8)$ \\
\hline A little & $0.44(0.1,1.85)$ & $0.43(0.1,1.83)$ & $0.6(0.14,2.61)$ & $0.59(0.14,2.56)$ & $0.5(0.18,1.39)$ & $0.5(0.18,1.38)$ \\
\hline Not at all & $0.26(0.06,1.1)$ & $0.25(0.06,1.08)$ & $0.3(0.07,1.28)$ & $0.29(0.07,1.28)$ & $0.26(0.09,0.73)$ & $0.26(0.09,0.73)$ \\
\hline \multicolumn{7}{|l|}{ Income } \\
\hline Q1 & 1 & 1 & 1 & 1 & 1 & 1 \\
\hline Q2 & $0.80(0.56,1.15)$ & $0.80(0.56,1.16)$ & $1.09(0.76,1.56)$ & $1.09(0.76,1.56)$ & $0.95(0.74,1.22)$ & $0.95(0.74,1.22)$ \\
\hline Q3 & $0.88(0.61,1.28)$ & $0.88(0.60,1.27)$ & $1.53(1.03,2.28)$ & $1.53(1.03,2.27)$ & $1.16(0.89,1.51)$ & $1.16(0.88,1.51)$ \\
\hline Q4 & $0.83(0.56,1.22)$ & $0.82(0.55,1.21)$ & $1.26(0.84,1.88)$ & $1.27(0.85,1.90)$ & $1.04(0.79,1.38)$ & $1.04(0.79,1.37)$ \\
\hline Q5 & $1.15(0.74,1.77)$ & $1.13(0.73,1.74)$ & $1.20(0.76,1.90)$ & $1.23(0.78,1.94)$ & $1.20(0.88,1.64)$ & $1.20(0.88,1.63)$ \\
\hline
\end{tabular}

Table 3: Age-adjusted and age unadjusted odds ratio(OR) from logistic regression analysis and their $95 \%$ confidence intervals(Cl) for care need by socio-demographic and socio-economic indicators among males, females and altogether.

However, among both sexes, income levels of older persons in Ghana showed weak and inconsistent association with care need in both ageunadjusted and age-adjusted models.

In contrast to men, care needs among women was associated with higher educational level such that college/university graduates were less likely to require care than those who had no formal education. Older adult females (60 years and above) need care more than adult females (50-59 years) and young adult females (18-49 years) respectively. Interestingly, men who are currently married need care more than other men whilst women who are widowed need care more than other women. Remarriage is increasingly prevalent, especially among men, with older widowed or divorced men more likely to remarry later in life than comparable older women. Thus marriage is normative for older men, and most men are married when they die (12).

While this study examined care need by socio-demographic and socioeconomic indicators amongst males and females, an alternative approach is to examine the implication of ageing and care needs, compressed morbidity and how long care need should be provided. It is evident that older people live much longer with significant burden of chronic disease disability and impairment and lose their ability to live independently (5).

Limitation: The SAGE Wave I in Ghana relied mostly on selfreported information and as care need is an objective experience, this may be a limitation of the study. Factors such as physical function, cognitive function, and co-morbidities which are important confounders to care were not included in the analysis. However, the responses to care questions provide reliable information for more in depth examination of care need among older persons in Ghana.

\section{Conclusion}

Care need was more prevalent among older female adults and showed predisposing and enabling factor disparities. The analysis revealed that women were mostly affected by socioeconomic difference in care need. Care need increased with age for both men and women. Those with lower education and the self-employed had a high prevalence of care need for both men and women. Also, older persons 
Citation: Saeed B, Yawson A, Nakua E, Agyei-Baffour P, Nsowah-Nuamah NNN, et al. (2015) Socioeconomic Differences in the Prevalence of Care Need among Older Persons in Ghana. Health Econ Outcome Res Open Access 1: 102. doi: 10.4172/2471-268x/1000102

with moderate, little or no money for daily living showed high rates of care need compared to those who had enough money. It is hoped that the gender disparities and other differences in care need among older persons identified in this analysis will guide the implementation of the 2010 National Aging Policy in Ghana. Importantly, SAGE can be used to further document impact and also as a monitoring mechanism for the 2010 National Aging Policy with SAGE Ghana Wave 2 planned for 2013/14.

\section{Acknowledgment}

We are grateful to all respondents and interviewers who made the SAGE survey in Ghana possible. Financial support was provided by the US Nationa Institute on Aging through Interagency Agreements (OGHA 04034785; YA132308-CN-0020; Y1-AG-1005-01) with the World Health Organization and a Research Project Grant (R01 AG034479-64401A1). WHO contributed financial and human resources to SAGE Ghana. The Ministry of Health, Ghana, is supportive of SAGE. The University of Ghana's Department of Community Health contributed training facilities, data entry support, and storage of materials. The Ghana Statistical Office provided the sampling information for the sampling frame and updates.

\section{References}

1. Health Policy Institute (2000) Georgetown University, analysis of data from the National Health Interview Survey.

2. United Nations Population Division (2011) DESA. World Population Prospects: The 2010 Revision. New York: United Nations.

3. Kowal P, Chatterii S, Naidoo N, Biritwum R, Wu Fan, et al. (2012) Data Resource Profile: The World Health Organization Study on global AGEing and adult health (SAGE). Int J Epidemiol 4: 1639-491

4. Zeng Y, Danan G, Land KC (2007) The association of childhood socioeconomic conditions with healthy longevity at the oldest old ages in China. Demography 44: 497518

5. Christensen K, Doblhammer G, Rau R, Vaupel JW (2009) Ageing populations: The challenges ahead. Lancet 374: 1196-1208.

6. Oxley (2009) H. Policies for Healthy Ageing: An. Overview. OECD Health Working Papers Paris: Organization for Economic Cooperation and Development

7. Kinsella K, He W (2009) An Aging World: 2008. Washington, DC: National Institute on Aging and U.S. Census Bureau.

8. National Institute on Aging (2007) Growing Older in America: The Health and Retirement Study. Washington, DC: U.S. Department of Health and Human Services.

9. Jones A (2002) The National Nursing Home Survey: 1999 summary. See comment in PubMed Commons below Vital Health Stat 13: 1-116.

10. R Stone (2000) Long-Term Care for the Elderly with Disabilities: Current Policy, Emerging Trends, and Implications for the Twenty-first Century.
11. Ministry of Employment and Social Welfare of Ghana (2008) Ghana National Ageing Policy. 'Ageing with Security and Dignity' Accra: Ministry of Employment and Social Welfare.

12. Arber S, Ginn J (2005) Gender Dimensions of Age Shift. In: Lewis Johnson M, Bengsten VL Coleman PG. The Cambridge Handbook of Age and Ageing 527-536.

13. Chatterji S, Kowal P, Mathers C, Naidoo N, Verdes E, et al. (2008) The health of aging populations in China and India. Health Affairs 27: 1052-1063.

14. Crimmins EM, Preston SH, Cohen B (2010) International Differences in Mortality at Older Ages. Dimensions and Sources. Washington, DC: The National Academies Press.

15. European Commission (2009) Ageing Report: Economic and Budgetary Projections for the EU-27 Member States (2008-2060). Brussels: European Communities.

16. Lafortune G, Balestat G (2007) Trends in Severe Disability Among Elderly People. Assessing the Evidence in 12 OECD Countries and the Future Implications.

17. Lopez AD, Mathers CD, Ezzati M, Jamison DT, Murray CJL (2006) Global Burden of Disease and Risk Factors. Washington, DC: The World Bank Group

18. Plassman BL, Langa KM, Fisher GG, Heeringa SG, Weir DR, et al. (2007) Prevalence of dementia in the United States: The aging, demographics, and memory study. Neuroepidemiology 29: 125-132.

19. Rohwedder S, Willis RJ (2010) Mental retirement. J Econ Perspect 24: 119-138.

20. http://www.who.int/healthinfo/survey/ageingdefnolder/en/

21. http://www.csrlaws.com/info-155.html [accessed 29.04.11] China Center for Labor and Environment.

22. http://www.china.org.cn/opinion/2011-03/08/content_22084542.htm

23. David de Vaus, Matthew Gray, David Stanton (2003) Measuring the value of unpaid household, caring and voluntary work of older Australians.

24. Hurria A (2009) Geriatric assessment in oncology practice. Journal of the American Geriatrics Society 57: S246-S249.

25. Pallis AG, Fortpied C, Wedding U, Van Nes MC, Penninckx B et al. (2010) EORTC elderly task force position paper: approach to the older cancer patient. European Journal of Cancer 46: 1502-1513.

26. Coale AJ (1982) A reassessment of world population trends. Popul Bull UN $1-16$.

27. Sahyoun NR (2001) "The Changing Profile of Nursing Home Residents: 19851997".

28. Scanlon W (1992 )“Possible Reforms for Financing Long-Term Care,” J Econ Perspect 6: 43-58.

29. US General Accounting Office (1999) Nursing Homes: Additional Steps Needed to Strengthen Enforcement of Federal Quality Standards. 